\title{
Correction to: Nursing Students' Experiences on Assessing the Sexuality of Patients: Mixed Method Study
}

\section{Yeter Durgun Ozan ${ }^{1}$ - Mesude Duman ${ }^{1}$ • Özlem Çiçek ${ }^{2}$}

Published online: 27 May 2019

๑) Springer Science+Business Media, LLC, part of Springer Nature 2019

\section{Correction to: Sexuality and Disability https://doi.org/10.1007/s11195-019-09567-6}

The original version of the article was published with incorrect tables. The correct version of the tables is presented in this erratum (Tables 1,2,3,4).

The original article can be found online at https://doi.org/10.1007/s11195-019-09567-6.

Özlem Çiçek

nr.ozlemcece@hotmail.com

Yeter Durgun Ozan

yeter_ozan@hotmail.com

Mesude Duman

mesudeduman@hotmail.com

1 Dicle University Ataturk Highschool of Health, Nursing Department, Diyarbakır, Turkey

2 Gyneocologic and Obstetric Nursing Department, Faculty of Nursing, Dokuz Eylul University, İzmir, Turkey 
Table 1 Descriptive characteristics of students

\begin{tabular}{llr}
\hline Characteristics & $\mathrm{n}$ & $\%$ \\
\hline Gender & & \\
Female & 55 & 52.9 \\
Male & 49 & 47.1 \\
Place of birth & & \\
City center & 64 & 61.5 \\
District & 20 & 19.2 \\
Village & 20 & 19.2 \\
Income level & & \\
Less income than expenses & 35 & 33.7 \\
Equal income and expenses & 60 & 57.7 \\
More income than expenses & 9 & 8.7 \\
Marital status & & \\
Single & 101 & 97.1 \\
Married & 3 & 2.9 \\
Family type & & 86.5 \\
Nuclear family & 90 & 12.5 \\
Extended family & 13 & 1.0 \\
Fragmented family & 1 & 65.4 \\
Places where they live & & 23.1 \\
With family & 68 & 11.5 \\
Dormitory & 24 & \\
Other (with relatives, alone) & 12 & \\
Age & $21.3 \pm 2.1$ & \\
\hline
\end{tabular}

${ }^{\mathrm{a}}$ Mean age 


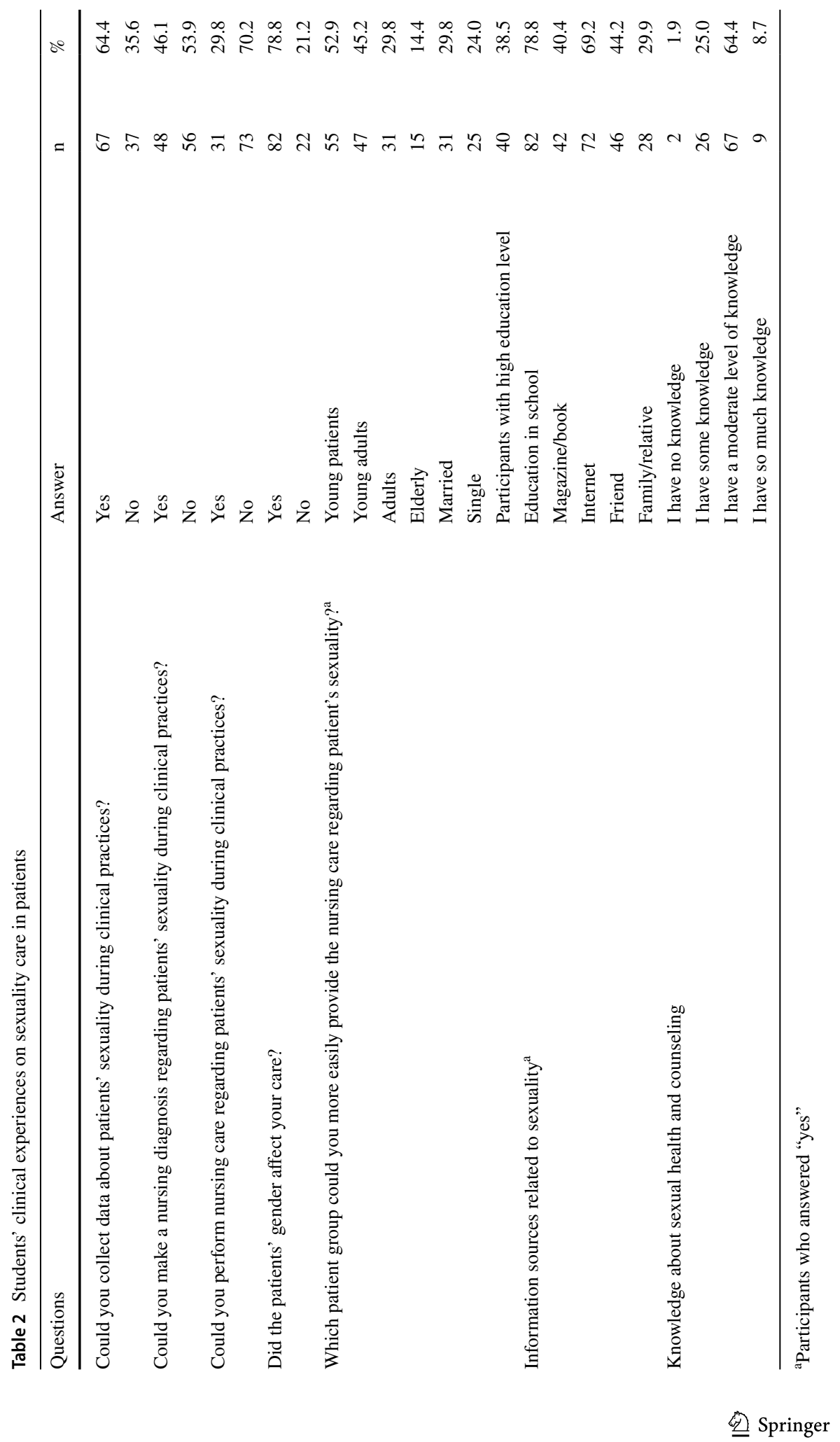




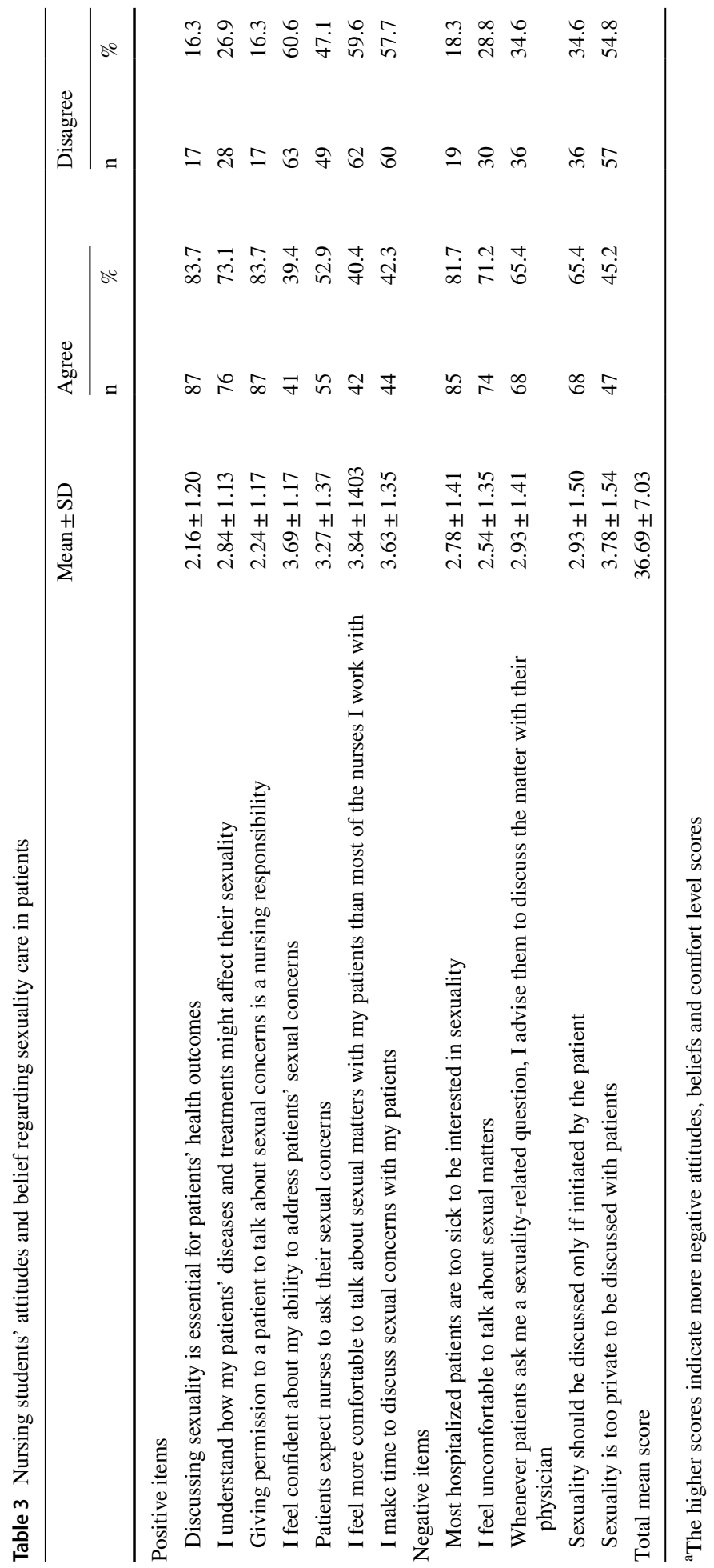




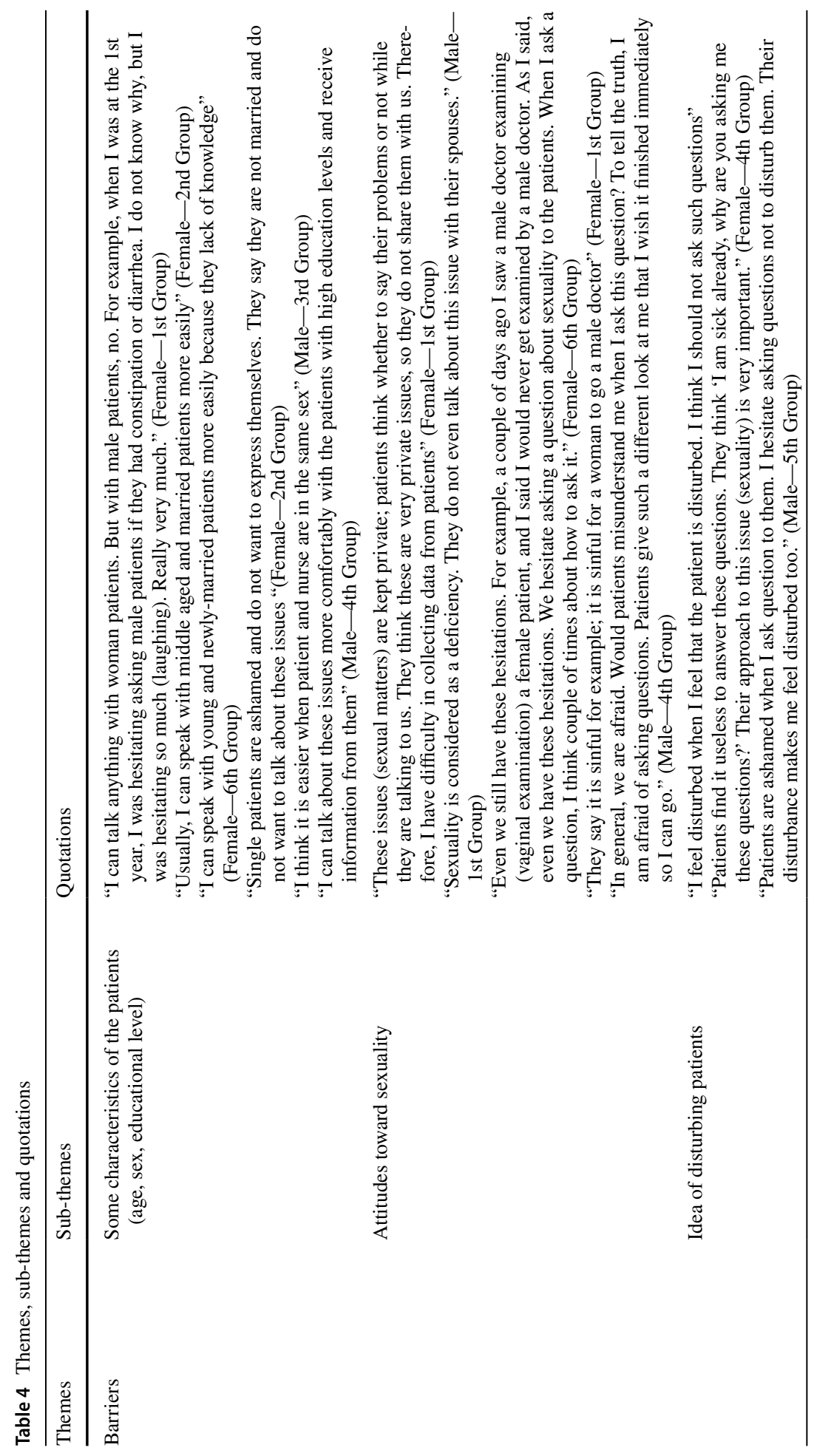




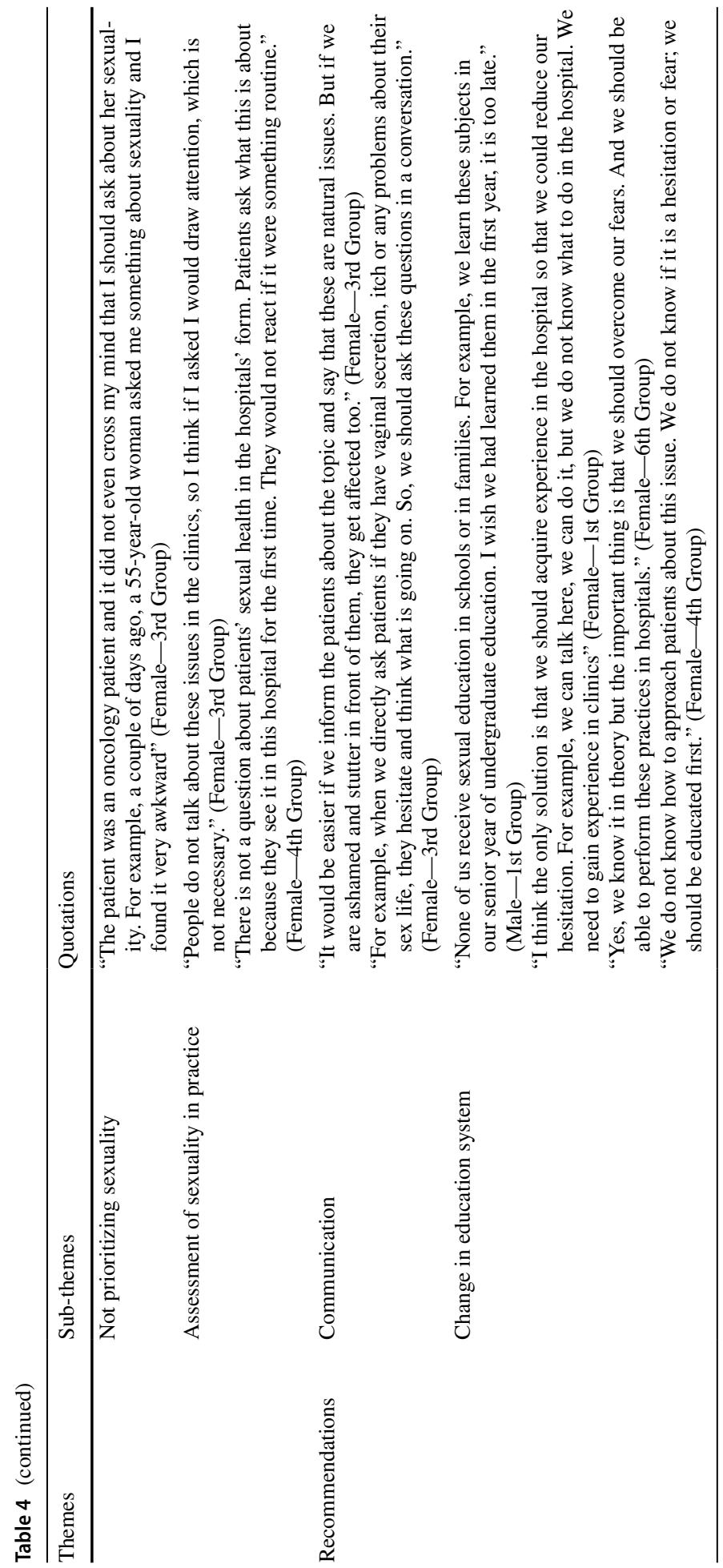


Publisher's Note Springer Nature remains neutral with regard to jurisdictional claims in published maps and institutional affiliations. 